\title{
Relationship between oral glucose tolerance and gastric emptying in normal healthy subjects
}

\author{
M.Horowitz ${ }^{1}$, M.A. L.Edelbroek ${ }^{2}$, J.M. Wishart ${ }^{1}$, J.W. Straathof ${ }^{1}$ \\ ${ }^{1}$ Department of Medicine, Royal Adelaide Hospital, Adelaide, Australia \\ ${ }^{2}$ Department of Surgery, University Hospital, Utrecht, The Netherlands
}

\begin{abstract}
Summary. The relationships between gastric emptying and intragastric distribution of glucose and oral glucose tolerance were evaluated in 16 healthy volunteers. While sitting in front of a gamma camera the subjects drank $350 \mathrm{ml}$ water containing $75 \mathrm{~g}$ glucose and $20 \mathrm{MBq}{ }^{99 \mathrm{~m}} \mathrm{Tc}$-sulphur colloid. Venous blood samples for measurement of plasma glucose, insulin and gastric inhibitory polypeptide were obtained at $2,2,5,10,15,30,45,60,75,90,105,120$ and $150 \mathrm{~min}$. Gastric emptying approximated a linear pattern after a short lag phase ( $3.3 \pm 0.8 \mathrm{~min})$. The $50 \%$ emptying time was inversely related to the proximal stomach $50 \%$ emptying time $(r=-0.55, p<0.05)$ and directly related to the retention in the distal stomach at $120 \mathrm{~min}(r=0.72, p<0.01)$. Peak plasma glucose was related to the amount emptied at $5 \mathrm{~min}$ $(r=0.58, p<0.05)$ and the area under the blood glucose curve between 0 and $30 \mathrm{~min}$ was related to the amount
\end{abstract}

emptied at $30 \mathrm{~min}(r=0.58, p<0.05)$. In contrast, plasma glucose at $120 \mathrm{~min}$ was inversely related to gastric emptying $(r=-0.56, p<0.05)$ and plasma insulin at $30 \mathrm{~min}$ $(r=-0.53, p<0.05)$. Plasma insulin at $120 \mathrm{~min}$ was inversely related $(r=-0.65, p<0.01)$ to gastric emptying. The increase in plasma gastric inhibitory polypeptide at $5 \mathrm{~min}$ was related directly to gastric emptying $(r=0.53, p<0.05)$. These results indicate in normal subjects that (i) gastric emptying accounts for about $34 \%$ of the variance in peak plasma glucose after a 75-g oral glucose load (ii) plasma glucose levels at $120 \mathrm{~min}$ are inversely, rather than directly, related to gastric emptying (iii) the distal stomach influences gastric emptying of glucose.

Key words: Oral glucose tolerance, gastric emptying, radionuclide methods.
The changes in blood glucose concentration which result from an oral carbohydrate load are theoretically dependent on the rate at which carbohydrate enters the small intestine, the rate of digestion and intestinal absorption of glucose and the rate of insulin-driven metabolism. It has been suggested that gastric emptying is a major factor in blood glucose homeostasis, in normal subjects and in patients with diabetes mellitus, by controlling the delivery of carbohydrate to the small intestinal epithelium [1-3]. This concept is supported by the observations that the reductions in postprandial blood glucose concentration due to ingestion of viscous polysaccharides [4] and intraduodenallipid infusion [5] are associated with retardation of gastric emptying.

In the absence of clear-cut hyperglycaemia (fasting glucose $>7.8 \mathrm{mmol} / \mathrm{l}$ or random glucose $>11.0 \mathrm{mmol} / \mathrm{l}$ ) the oral glucose tolerance test remains the most practical method for the diagnosis of diabetes [6,7]. To achieve international standardization the World Health Organization has recommended the use of a 75-g glucose load in adults, with interpretation based primarily on the 2 -h plasma glucose concentration [6]. There is indirect evidence that gas- tric emptying contributes to the variability in the results of oral glucose tolerance tests [2] and an inverse relationship between gastric emptying and blood glucose concentrations after solid carbohydrate meals has been observed in normal subjects [8]. However, the relationship between gastric emptying of glucose and plasma glucose concentrations during a "standard" oral glucose tolerance test has not been examined to our knowledge. It is therefore unclear whether the inter- and intra-individual variability of gastric emptying in normal subjects [9-11] has a significant impact on plasma glucose, particularly as blood glucose concentrations are tightly controlled in normal subjects.

The emptying of nutrient rich liquids, including carbohydrates, is closely regulated $[12,13]$. Gastric emptying is slowest when liquid meals have a high caloric content $[12$, 13 ] and this effect is mediated by the interaction of nutrients with mucosal receptors in the small intestine [1315]. As a result of this inhibition dextrose solutions ranging from $0.2-1.0 \mathrm{kcal} / \mathrm{ml}$ empty from the stomach at a linear, energy-constant, rate of about $2 \mathrm{kcal} / \mathrm{min}$ and dextrose infused intraduodenally produces inhibition of gas- 


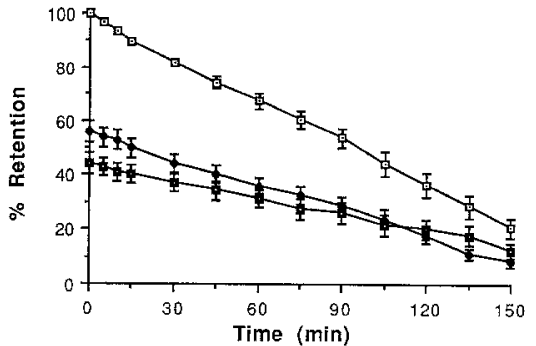

Fig.1 Gastric emptying from total $(\square)$, proximal $(\bullet)$ and distal (ש) $\operatorname{stomach}$ (mean values $\pm \mathrm{SEM}$ )

tric emptying in proportion to the amount of glucose delivered [13]. Both neural and hormonal pathways may be important in mediating the slowing of gastric emptying produced by the presence of nutrients in the small intestine [16-18]. Gastric inhibitory polypeptide (GIP), which is released during nutrient exposure in the small intestine may be important in regulating gastric emptying of carbohydrate, as well as in insulin release [17, 19, 20]. Recent studies have also provided insights into the motor mechanisms responsible for retardation of gastric emptying by the presence of glucose in the small intestine [16,21-23]. The traditional concept that the proximal stomach exerts the major control over liquid emptying, while the distal stomach regulates solid gastric emptying, has been challenged by studies demonstrating that gastric emptying of liquids is mainly pulsatile and associated with contractions of the antrum and duodenum [24,25]. These observations suggest that the content of the distal stomach may contribute to regulation of gastric emptying of glucose and other nutrient-containing liquid meals.

The major aims of our study were to examine the relationships between plasma levels of glucose, insulin and GIP and gastric emptying of a "standard" 75-g glucose load, and to determine the relationship between gastric emptying and intragastric distribution of glucose.

\section{Subjects and methods}

\section{Subjects}

Studies were carried out in 16 healthy volunteers ( 11 men, 5 women, median age 21 years, (range 18-35 years) and median body weight $73 \mathrm{~kg}$ (range $53-83 \mathrm{~kg}$ )) who were all non-smokers within $10 \%$ of ideal body weight (Metropolitan Life Insurance criteria) and had no history of gastrointestinal disease or surgery. None of the subjects was taking medication and all ate balanced meals with an intake of at least $250 \mathrm{~g}$ of carbohydrate per day. In the female subjects measurements of gastric emptying were performed during the follicular phase of the menstrual cycle. The study protocol was approved by the Ethics Committee of the Royal Adelaide Hospital and written informed consent was obtained from each subject.

\section{Protocol}

Each volunteer drank $350 \mathrm{ml}$ water containing $75 \mathrm{~g}$ glucose and $20 \mathrm{MBq}$ of ${ }^{99 \mathrm{~m}} \mathrm{Tc}$-sulphur colloid, while sitting comfortably in front of a scintillation camera. After an overnight fast ( $14 \mathrm{~h}$ for solids and $12 \mathrm{~h}$ for liquids) the meal was consumed within $1 \mathrm{~min}$ at 10.00 hours.
In each study gastric emptying data were acquired for at least $150 \mathrm{~min}$. Venous blood samples for measurement of plasma glucose, insulin and GIP were obtained via a cannula placed in an antecubital vein at $-2,2,5,10,15,30,45,60,75,90,105,120$ and 150 min following consumption of the test meal.

\section{Measurement of gastric emptying}

Gastric emptying data were collected in 30-s frames for the first $30 \mathrm{~min}$, followed by 3 -min frames for the subsequent $120 \mathrm{~min}$. Radionuclide data were corrected for subject movement, radionuclide decay, and gamma-ray attenuation, using previously described methods [9]. The total stomach region-of-interest was divided into proximal and distal regions using an automated computer program, with the proximal region corresponding to the fundus and proximal corpus and the distal region representing the distal corpus and antrum [26, 27]. Emptying curves (expressed as percentage retention of isotope vs time) were derived for total stomach, proximal stomach and distal stomach regions. From the emptying curves, several parameters were derived for subsequent statistical analysis. For the total stomach these were the duration of the lag phase before any isotope entered the duodenum, the $50 \%$ emptying time, and the amount of isotope remaining in the stomach at 5,15,30,60,120 and $150 \mathrm{~min}$. The lag phase was determined visually by the frame preceding that in which activity appeared in the proximal small intestine $[9$, $26]$. For the proximal stomach the $50 \%$ emptying time and the amount of isotope remaining at 5, 15,30,60,120 and $150 \mathrm{~min}$ and for the distal stomach the percentage of isotope remaining at 5, 15,30, 60,120 and $150 \mathrm{~min}$ were calculated [26]. Time zero was regarded as the time of completion of the glucose drink.

\section{Biochemicalmeasurements}

Plasma glucose, insulin and GIP levels were measured in the venous blood samples. Blood samples for measurement of insulin and GIP were collected on ice into EDTA tubes containing proteinase inhibitor (Trasylol; Bayer, Leverkeusen, FRG) and stored at $-70^{\circ} \mathrm{C}$ until assayed. Glucose was determined with the hexokinase enzymatic ri agent (Trace Scientific Pty Ltd, Baulkham Hills, New South Wales, Australia), GIP with a radioimmunoassay using an antiserum purchased from Pennisula Laboratories (Belmont, Calif., USA) [28] and insulin by radioimmunoassay (Phadeseph Insulin RIA; provided by Pharmacia Diagnostics, Uppsala, Sweden). Plasma GIP levels were expressed as a percentage of the basal level [28].

\section{Statistical analysis}

Data were evaluated using linear regression analysis and are expressed as mean \pm SEM. The area under the curve between 0 $30 \mathrm{~min}, 0-60 \mathrm{~min}$ and $0-120 \mathrm{~min}$ for plasma glucose, insulin and GIP were calculated using the trapezoidal rule. A $p$ value of less than 0.05 was considered significant.

\section{Results}

All subjects tolerated the study well without experiencing nausea. In one subject the venous blood sample obtained at 150 min was lost. Results for gastric emptying, plasma glucose, insulin and GIP are shown in Figures 1 and 2. Gastric emptying approximated a linear pattern after a short lag phase $(3.3 \pm 0.8 \mathrm{~min})$. The number of calories emptied from the stomach in the first $120 \mathrm{~min}$ was $190 \pm 14$ $(1.6 \pm 0.12 \mathrm{kcal} / \mathrm{min})$ and in the first $150 \mathrm{~min}$ was $238 \pm 10$ 
(a)

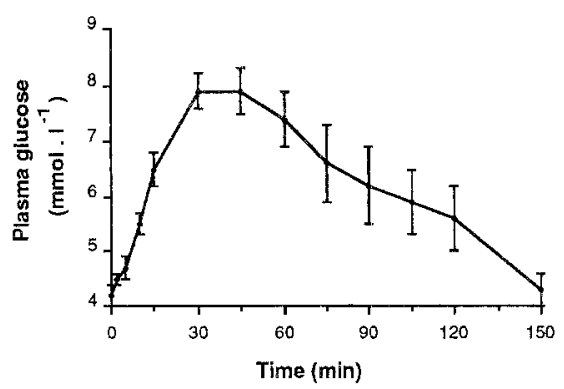

(b)

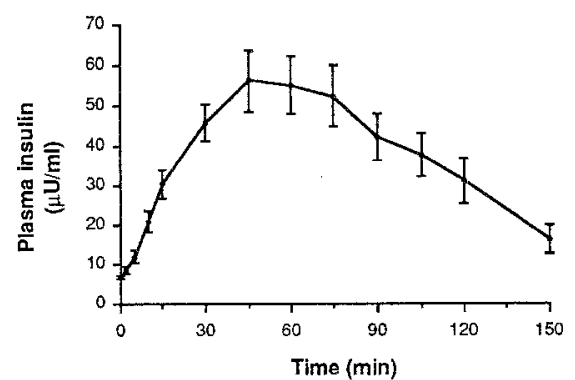

(c)

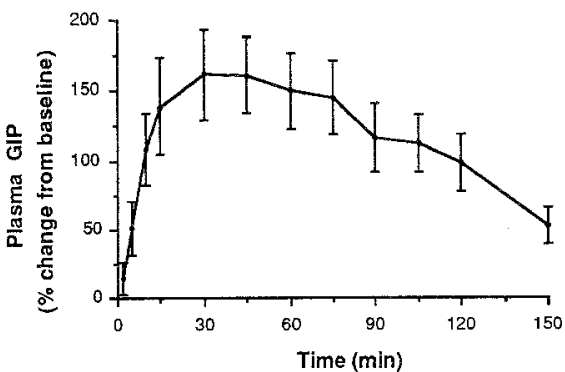

Fig. 2 (a-c). Plasma (a) glucose, (b) insulin and (c) gastric inhibitory peptide (GIP) (mean values \pm SEM)

$(1.6 \pm 0.07 \mathrm{kcal} / \mathrm{min})$. Gastric emptying from the proximal stomach also approximated a linear pattern. As expected there were significant increases in plasma glucose, insulin and GIP after the glucose drink.

\section{Relationship between gastric emptying and intragastric distribution of the meal}

The $50 \%$ emptying time for the total stomach was inversely related to the retention in the proximal stomach at $5 \mathrm{~min}(r=-0.61, p<0.01)$ and $15 \mathrm{~min}(r=-0.52$, $p<0.05)$ and the proximal stomach $50 \%$ emptying time $(r=-0.55, p<0.05)$, but not to the proximal stomach retention at $30 \mathrm{~min}(r=-0.36$, NS), $60 \mathrm{~min}(r=0.07$, NS $)$, $120 \mathrm{~min}(r=0.42, \mathrm{NS})$ or $150 \mathrm{~min}(r=0.25, \mathrm{NS})$, and directly related to the retention in the distal stomach at $5 \mathrm{~min}(r=0.58, p<0.05), 15 \mathrm{~min}(r=0.53, p<0.05)$, $30 \min (r=0.57, p<0.05), 60 \min (r=0.64, p<0.01)$, $120 \mathrm{~min}(r=0.72, p<0.01)$ and $150 \mathrm{~min}(r=0.71$, $p<0.01$ ) (Fig. 3). The retention of isotope in the proximal and distal stomach were inversely related at $5 \mathrm{~min}$ $(r=-0.98, p<0.001), 15 \min (r=-0.95, p<0.001)$, $30 \mathrm{~min}(r=-0.91, p<0.001)$ and $60 \mathrm{~min}(r=-0.66$, $p<0.001)$ but not $120 \mathrm{~min}(r=-0.01$, NS) or $150 \mathrm{~min}$ $(r=0.20, \mathrm{NS})$.

\section{Relationship between plasma glucose and gastric emptying}

Plasma glucose concentrations at $15 \mathrm{~min}(r=-0.61$, $p<0.01)$ and $30 \mathrm{~min}(r=-0.64, p<0.01)$ were inversely related to the retention of the glucose drink in the stomach at these times i.e. directly related to the rate of gastric emptying. There was no significant relationship $(r=-0.07$, NS) between plasma glucose and gastric emptying at $5 \mathrm{~min}$. The change in plasma glucose from baseline was inversely related to the retention of the meal in the stomach at $15 \mathrm{~min}(r=-0.52, p<0.05)$. Peak plasma glucose was inversely related to the retention of the meal at $5 \mathrm{~min}(r=-0.58, p<0.05)$ and $15 \mathrm{~min}(r=-$ $0.53, p<0.05)$ i.e. gastric emptying accounted for $34 \%$ of the variance $\left(r^{2}\right)$ in peak plasma glucose. The area under the plasma glucose curve between 0 and $30 \mathrm{~min}$ was also inversely related to the retention of the meal in the stomach at this time $(r=-0.58, p<0.05)$ (Fig. $4 \mathrm{a})$. In contrast, both the plasma glucose concentration and the change in glucose concentration from baseline at $105 \mathrm{~min}(r \geq 0.50$, $p<0.05), 120 \mathrm{~min}(r \geq 0.56, p<0.05)$ and $150 \mathrm{~min}$ $(r \geq 0.82, p<0.001)$ were directly related to the retention of the meal in the stomach at these times (Fig. 4 b) i.e. inversely related to the rate of gastric emptying. There was a weak inverse relationship between the amount of the meal that emptied between $30 \mathrm{~min}$ and $150 \mathrm{~min}$ and the mean plasma glucose during this time $(r=-0.48$, $p=0.05)$.

\section{Relationship between plasma insulin and gastric emptying}

There was no significant relationship between plasma insulin concentrations, or the change in plasma insulin from baseline at $5 \min (r=-0.01, \mathrm{NS}) 15 \min (r \geq 0.03$, NS) or $30 \mathrm{~min}(r \geq-0.17, \mathrm{NS})$ and the retention of the meal in the stomach at these times. Plasma insulin and the change in plasma insulin from baseline at $120 \mathrm{~min}(r \geq 0.65$, $p<0.01)$ and $150 \mathrm{~min}(r \geq 0.73, p<0.01)$ were both related to the retention of isotope in the stomach at these times. There was no significant relationship between either peak insulin levels or the area under the plasma insulin curve and gastric emptying.

\section{Relationship between plasma GIP and gastric emptying}

The rise in GIP at $5 \mathrm{~min}$, was inversely related $(r=-0.51$, $p<0.05$ ) to the retention of the meal in the stomach at this time.

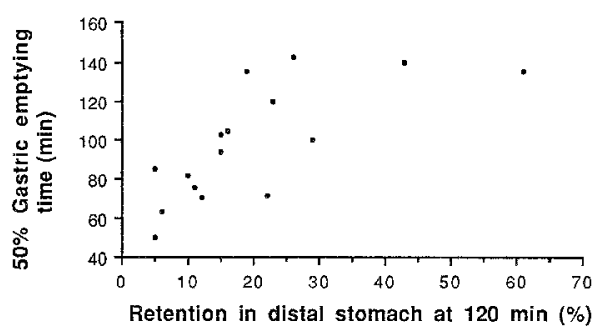

Fig. 3. Relationship between the $50 \%$ gastric emptying time from the total stomach and the retention of the meal in the distal stomach at $120 \mathrm{~min}(r=0.72, p<0.001)$ 

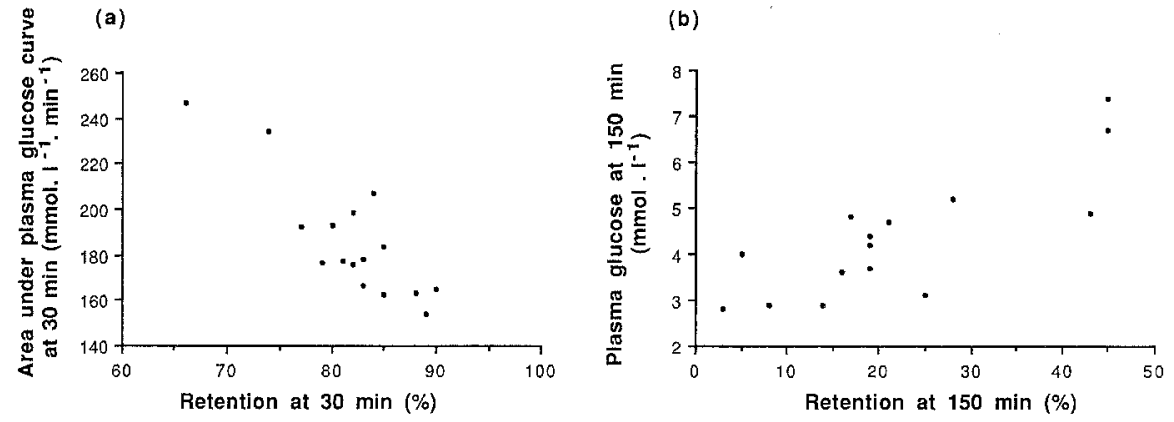

Fig.4(a, b). Relationship between (a) the area under the plasma glucose concentration curve between 0 and $30 \mathrm{~min}$ and the retention of the meal in the stomach at $30 \min (r=-0.58, p<0.05)$ and (b) the plasma glucose concentration and the retention of the meal in the stomach at $150 \min (r=0.82, p<0.001)$

\section{Relationships between biochemical measurements}

Plasma glucose and insulin levels were significantly related at 5, 105, 120 and $150 \mathrm{~min}(r \geq 0.50, p<0.05)$. The area under the curves for glucose and insulin between 0 and $30 \mathrm{~min}$ were also related $(r=0.49, p<0.05)$. The plasma glucose concentration at 120 min was inversely related $(r=-0.53, p<0.05)$ to the plasma insulin at $30 \mathrm{~min}$. There was no significant relationship between peak glucose and insulin levels $(r=0.35$, NS). Plasma insulin and glucose at $5 \mathrm{~min}$ were both related to plasma GIP at this time $(r=0.53, p<0.05$ and $r=0.47, p<0.05$, respectively).

\section{Discussion}

The results of this study indicate in normal subjects that: (i) gastric emptying accounts for about $34 \%$ of the variance in peak plasma glucose after a $75-\mathrm{g}$ oral glucose load, so that peak plasma glucose is greater if the initial rate of gastric emptying is more rapid (ii) plasma glucose at $120 \mathrm{~min}$ is inversely, rather than directly, related to the rate of gastric emptying of glucose (iii) the distal stomach influences gastric emptying of glucose.

The rate of absorption of a number of intestinally absorbed solutes, including paracetamol [29] and alcohol [30] is dependent on the rate of gastric emptying. It was suggested in 1915 that changes in gastric emptying may account for some of the documented variability in the blood glucose response to an oral glucose load [31] and subsequent studies $[2,4,8]$ have supported this concept. Thompson et al. [2] suggested that the blood glucose concentration after a $50 \mathrm{-g}$ glucose tolerance test in healthy subjects is dependent on the phase of fasting gastric motor activity which exists at the time of glucose ingestion. Fasting antral motor activity is cyclical and consists of three phases which have a cycle time of about $100 \mathrm{~min}$ : phase 1 motor quiescence, phase 2 irregular contractions and phase 3 regular high amplitude contractions at the maximal rate of about 3 per min for about 5 min [32]. Thompson et al. [2] reported that when normal subjects were given $50 \mathrm{~g}$ glucose in $200 \mathrm{ml}$ water, peak blood glucose concentrations were higher when the glucose was ingested during phase 2 , when compared to phase 1 and provided indirect evidence that this difference reflected more rapid gastric emptying during phase 2 . More recent studies have demonstrated that gastric emptying of small volumes of low nutrient liquids is significantly faster during phase 2 than in phase $1[33,34]$. However, phase-related changes in gastric emptying appear to have much less effect on gastric emptying when ingested volumes are greater than $200 \mathrm{ml}$ [34]. The initial rate of gastric emptying of nutrient-containing liquids including glucose may be faster than the subsequent rate $[13,14]$. While this may possibly reflect the phase of fasting gastric motility, the rate of initial emptying of nutrient liquids has been shown to be related to the volume of the meal [12]. This early rapid emptying phase may relate to a delay in feedback inhibition of gastric emptying by small intestinal receptors $[12,21]$.

It has been suggested that, after the initial emptying phase, the rate of gastric emptying of carbohydrate-containing liquids is calibrated precisely at about $2 \mathrm{kcal} / \mathrm{min}$ $[12,13,35]$, comparable with the rate of $1.6 \mathrm{kcal} / \mathrm{min}$ observed in our study, and that the magnitude of the delay in gastric emptying produced by the presence of glucose in the small intestine is dependent solely on the number and site of receptors in the small intestine $[15,36]$. This hypothesis has been challenged by recent observations that feedback from these receptors may be influenced by patterns of prior nutrient intake [23, 37]. For example, in healthy humans gastric emptying of glucose is faster after dietary supplementation with glucose for 3 days [37]. Our study has demonstrated that the initial rate of gastric emptying of glucose is a major determinant of the subsequent blood glucose response in normal subjects, as there was a significant relationship between peak plasma glucose and the magnitude of the early phase of gastric emptying. In contrast, the plasma glucose concentration at $120 \mathrm{~min}$, which is characteristically used for diagnostic purposes, was inversely related to gastric emptying and this presumably reflected the higher insulin levels achieved earlier. The results clearly indicate that in normal subjects differences in gastric emptying are reflected in postprandial plasma glucose and insulin levels.

At present protocols for oral glucose tolerance testing vary in the amount of glucose given to the patient, the time(s) at which blood is sampled and the interpretation of results $[3,6,7]$. Oral glucose tolerance may be more reproducible with higher glucose loads, perhaps because the initial rate of gastric emptying is more predictable $[13,38]$, but the use of more glucose is also associated with a higher prevalence of nausea which may influence gastric emptying and thereby the results of the test [3]. We did not evaluate the relationship between gastric emptying and the 
plasma glucose response to other glucose loads. However, because gastric emptying of glucose is usually independent of the volume and concentration of the glucose solution $[12,13,35]$, a significant relationship would be expected. This concept is supported by the inverse relationship between gastric emptying and plasma insulin concentrations observed in other studies [8,39,40]. It is logical to assume that because of deficient counterregulatory responses in diabetic patients, gastric emptying will have a greater impact on glucose tolerance and a significant relationship between gastric emptying and insulin requirement in the first $2 \mathrm{~h}$ after a meal has been observed in patients with Type 1 (insulin-dependent) diabetes [41]. Factors which modify gastric emptying in normal subjects including cigarette smoking, posture, stress and many drugs [18] are likely to have a major impact on the results of oral glucose tolerance tests and the glycaemic response to carbohydrate-containing meals in diabetic patients. It is also possible that differences in previous carbohydrate intake contribute to the inter- and intra-individual variability of gastric emptying of carbohydrate and blood glucose responses $[9,10,37,38]$.

The blood glucose concentration may also affect gastric emptying. It has recently been demonstrated that the rate of gastric emptying in diabetes is slower during hyperglycaemia ( $15 \mathrm{mmol} / \mathrm{l})$ than during euglycaemia [27]. In normal subjects induced hyperglycaemia also retards gastric emptying [42] and this delay may reflect suppression of antral pressure waves and stimulation of pressure waves localized to the pylorus [43]. At present it is not clear whether variations in blood glucose within the normal range affect gastric emptying of nutrients, although this seems likely as fasting antral motility is suppressed by serum glucose levels as low as $7.8 \mathrm{mmol} / 1$ in normal subjects [44]. The observation of an inverse relationship between mean plasma glucose between 30 and 150 min and gastric emptying in our study is consistent with the hypothesis that hyperglycaemia may slow absorption of carbohydrate by retarding gastric emptying.

The roles of the proximal and distal stomach in the emptying of solids and liquids from the stomach are unclear $[18,26,45]$. It has been suggested that the proximal stomach exerts the major influence on gastric emptying of liquids $[22,46]$. Short-term intraduodenal infusion of glucose is, however, also associated with suppression of antral pressure waves, stimulation of phasic pressure waves isolated to the pylorus and an increase in basal pyloric pressure $[16,21]$. Although emptying of the distal stomach is difficult to evaluate by scintigraphic methods because of the variable input from the proximal stomach, our observation that gastric emptying of glucose was related to the retention of the meal in the distal stomach, but not the proximal stomach at $120 \mathrm{~min}$ and $150 \mathrm{~min}$ suggests that the distal stomach also influences gastric emptying of nutrient-containing liquid meals [26].

The observation that the rise in plasma GIP at 5 min was related to gastric emptying and plasma insulin is consistent with current concepts that GIP release in response to an oral glucose load is a reflection of the early phase of gastric emptying, rather than GIP being a determinant of gastric emptying $[19,20]$, and that GIP potentiates insulin release
[17]. Other hormones may regulate gastricemptying of glucose $[39,40,47,48]$. In particular, exogenous cholecystokinin octapeptide reduces glucose and insulin levels after an oral glucose load in both normal subjects [47] and patients with early Type 2 (non-insulin-dependent) diabetes [40] by slowing gastric emptying. The concept that endogenously released cholecystokinin influences gastric emptying of glucose has been strengthened by the observation that the specific cholecystokinin antagonist, loxiglumide, accelerates gastric emptying of glucose and increases postprandial plasma insulin concentrations [39].

Acknowledgements. This work was supported by grants from the National Health and Medical Research Council of Australia and the Rebecca L. Cooper Medical Research Foundation Ltd. We wish to thank Ms T. Piscioneri for typing the manuscript, Dr. H. Morris for support in performing the GIP assays and Dr. B. Chatterton for permitting the gastric emptying measurements to be performed in his department.

\section{References}

1. Horowitz M, Edelbroek M, Fraser R, Maddox A, Wishart J (1991) Disordered gastric motor function in diabetes mellitus recent insights into prevalence, pathophysiology, clinical relevance and treatment. Scand J Gastroenterol 26: 673-684

2. Thompson DG, Wingate DL, Thomas M, Harrison D (1982) Gastric emptying as a determinant of the oral glucose tolerance test. Gastroenterology 82: $51-55$

3. Schwartz JG, Phillips WT, Aghebat-Khairy B (1990) Revision of the oral glucose tolerance test: a pilot study. Clin Chem 36: 125128

4. Meyer JH, Gu YG, Jehn D, Taylor IL (1988) Intragastric vs intraintestinal viscous polymers and glucose tolerance after liquid meals of glucose. Am J Clin Nutr 48: 260-266

5. Welch I McL, Bruce C, Hill SE, Read NW (1987) Duodenal and ileal lipid suppresses postprandial blood glucose and insulin responses in man: possible implications for the dietary management of diabetes mellitus. Clin Sci 72:209-216

6. WHO Study Group (1985) Diabetes mellitus. World Health Organisation Technical Report Series 727, Geneva

7. Harris M, and members of NIH Diabetes Data Group Workshop (1979) Classification and diagnosis of diabetes mellitus and other categories of glucose intolerance. Diabetes 28: 1039-1057

8. Mourot J, Thouvenot P, Couet C, Antoine JM, Krobicka A, Debry G (1988) Relationship between the rate of gastric emptying and glucose and insulin responses to starchy foods in young healthy adults. Am J Clin Nutr 48: 1035-1040

9. Collins PJ, Horowitz M, Cook DJ, Harding PE, Shearman DJC (1983) Gastric emptying in normal subjects. A reproducible technique using a single scintillation camera and computer system. Gut 24: 1117-1125

10. Brophy CM, Moore JG, Christian PE, Egger MJ, Taylor AT (1986) Variability of gastric emptying measurements in man employing standardized radiolabelled meals. Dig Dis Sci 31:799-806

11. Horowitz M, Collins PJ, Shearman DJC (1985) Disorders of gastric emptying and the use of radionuclide techniques. Arch Int Med 145: 1467-1475

12. Hunt JN, Smith JL, Jiang CL (1985) Effect of meal volume and energy density on the gastric emptying of carbohydrates. Gastroenterology 89: 1326-1330

13. Brener W, Hendrix TR, McHugh PR (1983) Regulation of the gastric emptying of glucose. Gastroenterology 85:76-82

14. Hunt JN, Spurrell WR (1951) The pattern of emptying of the human stomach. J Physiol 113: 157-168

15. Lin HC, Doty JE, Reedy TJ, Meyer JH (1989) Inhibition of gastric emptying by glucose depends on length of intestine exposed to nutrient. Am J Physiol 256: G404-G411 
16. Fone DR, Horowitz M, Dent J, Read NW, Heddle R (1989) Pyloric motor response to intraduodenal dextrose involves muscarinic mechanisms. Gastroenterology 97: 83-90

17. Thor P, Laskiewicz J, Konturek JW, Konturek SJ, Creutzfeldt W (1987) Role of GIP and insulin in glucose-induced changes in intestinal motility patterns. Am J Physiol 252: G8-G12

18. Horowitz M, Dent J (1991) Disordered gastric emptying: mechanical basis, assessment and treatment. Bailliere's Clin Gastroenterol 5:371-407

19. Salminen EK, Salminen SJ, Porkka L, Kwasowski P, Marks V, Koivistoinen PE (1989) Xylitol vs glucose: effect on the rate of gastric emptying and motilin, insulin, and gastric inhibitory polypeptide release. Am J Clin Nutr 49: 1228-1232

20. Cataland S, Crockett SE, Brown JC, Mazzaferri EL (1974) Gastric inhibitory polypeptide (GIP) stimulation by oral glucose in man. J Clin Endocrinol Metab 39: 223-228

21. Heddle R, Fone D, Dent J, Horowitz M (1988) Stimulation of pyloric motility by intraduodenal dextrose in normal subjects. Gut 29: $1349-1357$

22. Azpiroz F, Malagelada J-R (1985) Intestinal control of gastric tone. Am J Physiol 249: G501-G509

23. Edelbroek M, Horowitz M, Fraser R et al. (1992) Adaptive changes in the pyloric motor response to intraduodenal dextrose in normal subjects. Gastroenterology 103: 1283-1290

24. Houghton LA, Read NW, Heddle R et al. (1988) Motor activity of the gastric antrum, pylorus, and duodenum under fasted conditions and after a liquid meal. Gastroenterology 94: 1276-1284

25. Malbert CH, Ruckebusch Y (1991) Relationships between pressure and flow across the gastroduodenal junction in the dog. Am J Physiol 264: G653-G657

26. Collins PJ, Houghton LA, Read NW et al. (1991) Role of proximal and distal stomach in mixed solid and liquid meal emptying. Gut 32:615-619

27. Fraser R, Horowitz M, Maddox A, Chatterton B, Harding P, Dent J (1990) Hyperglycaemia slows gastric emptying in type 1 (insulin-dependent) diabetes mellitus. Diabetologia 33: 675-680

28. Wishart JM, Morris HA, Horowitz M (1992) Radioimmunoassay of gastric inhibitory peptide in plasma. Clin Chem 38: 2156-2157

29. Nimmo WS (1976) Drugs, diseases and altered gastric emptying. Clin Pharmacokinet 1: 189-203

30. Horowitz M, Maddox A, Bochner M et al. (1989) Relationships between gastric emptying of solid and caloric liquid meals and alcohol absorption. Am J Physiol 257: G291-G298

31. Woodyatt RT, Sansum WD, Wilder RM (1915) Prolonged and accurately timed intravenous injection of sugar. JAMA 65:20672070

32. Wingate DL (1981) Backwards and forwards with the migrating complex. Dig Dis Sci 26: 641-666

33. Schindlbeck NE, Heinrich C, Muller-Lissner SA (1989) Relation between fasting antroduodenal motility and transpyloric fluid movements. Am J Physiol 257: G198-G201

34. Oberle RL, Chen T-S, Lloyd C et al. (1990) The influence of the interdigestive migrating myoelectric complex on the gastric emptying of liquids. Gastroenterology 99: 1275-1282
35. Phillips WT, Schwartz JG, Blumhardt R, McMahan CA (1991) Linear gastric emptying of hyperosmolar glucose solutions. J Nucl Med 32: 377-381

36. Lin HC, Moller NA, Wolinsky MM, Kim BH, Doty JE, Meyer $\mathrm{JH}$ (1992) Sustained slowing effect of lentils on gastric emptying of solids in humans and dogs. Gastroenterology 102: 787-792

37. Cunningham KM, Horowitz M, Read NW (1991) The effect of short-term dietary supplementation with glucose on gastric emptying in humans. Br J Nutr 65: 15-19

38. Toeller M, Knussmann R (1973) Reproducibility of oral glucose tolerance tests with three different loads. Diabetologia 9: 102107

39. Fried M, Schwizer W, Beglinger C, Keiler U, Jansen JB, Lamers CB (1991) Physiological role of cholecystokinin on postprandial insulin secretion and gastric meal emptying in man. Studies with the cholecystokinin receptor antagonist loxiglumide. Diabetologia $34: 721-726$

40. Phillips WT, Schwartz JG, McMahan CA (1993) Reduced postprandial blood glucose levels in recently diagnosed non-insulindependent diabetics secondary to pharmacologically induced delayed gastric emptying. Dig Dis Sci 38: 51-58

41. Hongo M, Satake K, Sanoyama K et al. (1987) Regulation of insulin demand by gastric emptying in diabetics. Gastroenterology 92: 1440 (Abstract)

42. MacGregor JL, Gueller R, Watts HD, Meyer JH (1976) The effect of acute hyperglycaemia on gastric emptying in man. Gastroenterology 70: 190-196

43. Fraser R, Horowitz M, Dent J (1991) Hyperglycaemia stimulates pyloric motility in normal subjects. Gut 32: 475-478

44. Barnett JL, Owyang C (1988) Serum glucose concentration as a modulator of interdigestive gastric motility. Gastroenterology 94: 739-744

45. Meyer JH (1987) Motility of the stomach and gastroduodenal junction. In: Johnson LR (ed) Physiology of the gastrointestinal tract. 2nd edn, vol 1. Raven Press, New York, pp 613-630

46. Kelly KA (1980) Gastric emptying of liquids and solids: roles of proximal and distal stomach. Am J Physiol 239: G71-G76

47. Liddle RA, Rushakoff RJ, Morita ET, Beccaria L, Carter JD, Goldfine ID (1988) Physiological role for cholecystokinin in reducing postprandial hyperglycaemia in humans. J Clin Invest 81 : 1675-1681

48. Orskov C (1992) Glucagon-like-peptide-1, a new hormone of the entero-insular axis. Diabetologia 35: 701-711

Received: 18 January 1993

and in revised form: 26 April 1993

Assoc. Prof. M. Horowitz

Department of Medicine

Royal Adelaide Hospital

North Terrace

Adelaide, South Australia

Australia 5000 